\title{
Energetic Analysis of Two Thermal Power Plants with Six and Seven Heaters
}

\author{
Miguel Toledo1, Juan Abugaber1, Raúl Lugo², Martín Salazar3, \\ Alfredo Rodríguez ${ }^{4}$, Aldo Rueda ${ }^{1}$ \\ ${ }^{1}$ Applied Hydraulics and Thermal Engineering Laboratory, National Polytechnics Institute, Mexico City, Mexico \\ ${ }^{2}$ Hydraulic Engineering and Process Department, Metropolitan Autonomous University, Mexico City, Mexico \\ ${ }^{3}$ Industrial Engineering and Mechatronics Department, Tecnológico de Estudios Superiores de Ecatepec, \\ Ecatepec de Morelos, Mexico \\ ${ }^{4}$ Centro de Investigación en Ingeniería y Ciencias Aplicadas, CIICAp/UAEM, Cuernavaca, Mexico \\ Email: mtv49@yahoo.com
}

Received 4 October 2013; revised 7 November 2013; accepted 16 November 2013

Copyright (c) 2014 Miguel Toledo et al. This is an open access article distributed under the Creative Commons Attribution License, which permits unrestricted use, distribution, and reproduction in any medium, provided the original work is properly cited. In accordance of the Creative Commons Attribution License all Copyrights () 2014 are reserved for SCIRP and the owner of the intellectual property Miguel Toledo et al. All Copyright (C) 2014 are guarded by law and by SCIRP as a guardian.

\begin{abstract}
An energetic analysis of two power plants with six and seven heaters was realized in this work and also a feedwater heater was taking into consideration. This analysis considered the temperature and pressure ranges under which power generating plants work. The unit thermal consumption (UTC), the specific fuel consumption (SFC) and the specific steam consumption (SSC) were obtained for power generation. The energetic analysis to the cycles of steam with regeneration with six and seven heaters was realized. There was a difference of $0.5 \%$ in the values of UTC, SFC and SSC when the pressures of condensation changed. Also an analysis of the behavior of the thermal efficiency in relation to the rise of numbers of heater from two to seven is presented.
\end{abstract}

\section{Keywords}

Energetic Analysis; Feedwater Heater; Thermal Efficiency; Rankine Cycle

\section{Introduction}

In Mexico, most of the thermoelectrical plants work according to Rankine cycle with superheat, reheat and regeneration. Many of these plants are working with heating with six and seven heaters and one of them is 
feedwater heater. Generally the feedwater heater is placed on conditions of a medium pressure ranging from 10 to 15 bars and a temperature from $150^{\circ} \mathrm{C}$ to $200^{\circ} \mathrm{C}$. Currently, $40 \%$ of the electrical power is generated in thermoelectricals. According to this, in the present work, an energetic study in thermal plants was realized in order to predict the thermal efficiency under operating conditions and some environmental variables. A thermodynamic analysis of a Rankine cycle reheat of steam power plant is conducted in terms of the first law of thermodynamic analysis (i.e. energy analysis) and the second law analysis (i.e. exergy analysis). Two heaters considering the operating parameters were used but design parameters were not considered. Steam quality at the end of the expansion are less than $0.88[1,2]$. If a thermal plant works under these conditions the steam turbine would present erosion zones.

The power generation plants have two limitations in their operation: the technological and environmental. Most thermoelectrical plants in Mexico operate in conditions of the inlet to the steam turbine of 124 bar and a temperature above $538^{\circ} \mathrm{C}$, and different conditions of condensing pressure depending of the environment conditions of the place where they are installed, although the newer plants work at a pressure of 160 bar and a temperature of $600^{\circ} \mathrm{C}$ [3]. An energetic analysis is realized at two power plants with six and seven heaters, placing in the same order with a feedwater heater. This analysis considers the temperature and pressure ranges at which power generating plants work, to obtain the unitary heat consumption, specific consumption of steam and fuel required to generate power [4]. It also includes an analysis of how many heaters are necessary in the operation of a power plant, and in this manner, a simulation of operating plants with two heaters and the simulation of operating plants up to six heaters and one feedwater heater was realized [5]. The energetic analysis is performed using mass and energy balances in each of the units that constitute the steam cycle, which serve as the basis for a computer program in Visual Basic platform. For this analysis, the operating parameters of the Power station in Altamira, Tamaulipas are considered to operate seven heaters and the one in the city of Lerdo in Durango to operate with six heaters, both power stations generate $160 \mathrm{MW}$ [6]. Likewise, the same analysis is performed in power stations that operate with less number of heaters, varying the condensing pressure and the pressure at the inlet of the steam turbine but maintaining constantly all other conditions of operation. Table 1 shows the operating conditions to which the energetic analysis is realized.

\section{Steam Cycles}

The steam cycles are analyzed in Rankine cycles with superheat, reheating and regeneration with arrangements on the train heating of 2, 3, 4, 5, 6 and 7 heaters, the evaluation is at the same operating conditions and using the optimum pressure ratio $\mathrm{p} 3 / \mathrm{p} 1$ as design condition making sure that in the last stage of expansion in the turbine the steam has a higher quality than 0.88 .

The temperature entropy diagrams of power stations with six and seven heaters are shown in Figures 1 and 2. The feedwater heater is placed in the third position on the condenser. In the following figures the six different processes of heating, superheat, reheat, regeneration, pumping and expansion of steam are shown

The regeneration in the Rankine cycles has advantages because it increases the feed water temperature on its way back to the heater and, as a result, it increases the thermal efficiency of the process of feed heating and because it requires less fuel flow to generate power.

In the Rankine cycle with regeneration, the steam at high pressure and the temperature produced in the steam generator is fed into the turbine where expands its volume in each one of its stages, then part of this steam is taking out to take advantage of its high temperature to preheat the feed line of the steam generator.

In steam turbine plants, several feed heaters are introduced. The process results in an improvement in the thermal efficiency plant.

Table 1. Operating Conditions.
\begin{tabular}{cccc}
\multicolumn{5}{c}{ Operating Conditions } \\
\hline \multicolumn{2}{c}{ Design Conditions } & \multicolumn{3}{c}{538} \\
$\mathrm{~h}_{\mathrm{Ts}}$ & 0.9 & $\mathrm{~T}_{1}\left({ }^{\circ} \mathrm{C}\right)$ & 124.85 \\
$\mathrm{~h}_{\mathrm{Pump}}$ & 0.8 & $\mathrm{p}_{1}(\mathrm{bar})$ & 0.11 \\
$\mathrm{p}_{3} / \mathrm{p}_{1}$ & 0.25 & $\mathrm{P}_{\text {cond }}(\mathrm{bar})$ & 160 \\
$\mathrm{TTD}_{\mathrm{HP}}\left({ }^{\circ} \mathrm{C}\right)$ & 0 & $\mathrm{PP}(\mathrm{MW})$ & $41860 \mathrm{~kJ} / \mathrm{kg}$ \\
$\mathrm{TTD}_{\mathrm{LP}}\left({ }^{\circ} \mathrm{C}\right)$ & -2.77 & $\mathrm{LHV}_{\text {gas }}(\mathrm{kJ} / \mathrm{kg})$ & \\
\hline
\end{tabular}




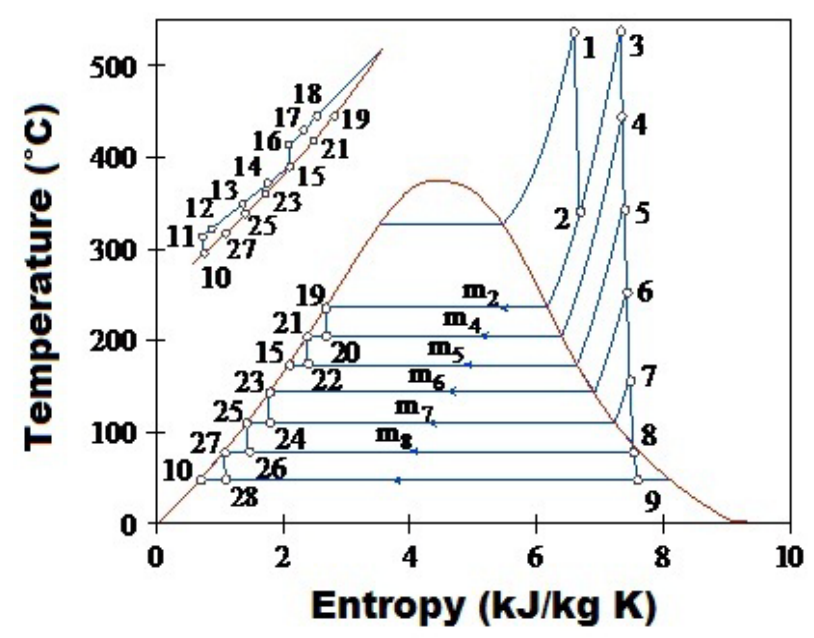

Figure 1. Diagram of temperature and entropy of regenerative cycle with six heaters.

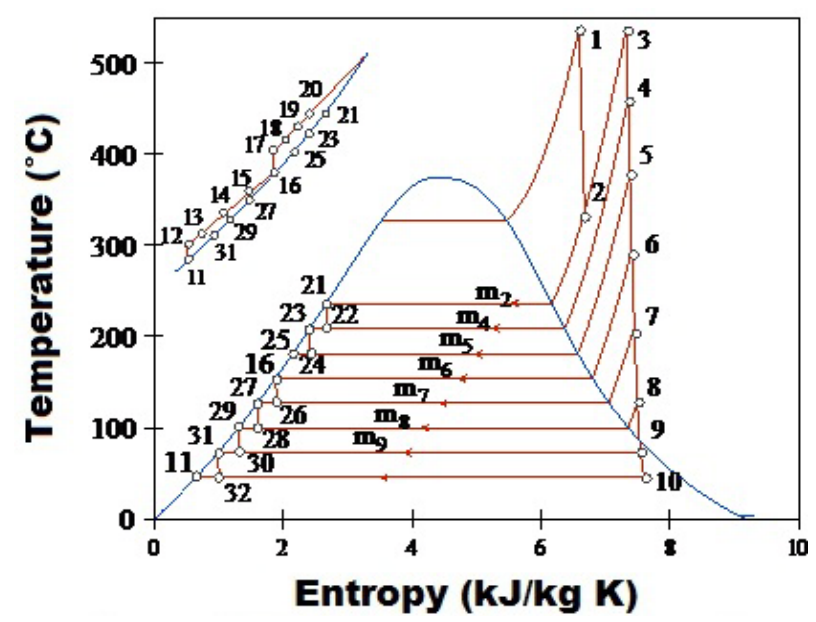

Figure 2. Diagram of temperature and entropy of regenerative cycle with seven heaters.

With the Rankine cycles, superheated, reheating and regeneration and the operating conditions of Table 1, a parametric analysis was realized varying the condensation pressures and input to the steam turbine, getting as a result the thermal efficiency, unitary thermal consumption, the fuel flow, the specific consumption of fuel and steam, which are defined by the following equations:

Thermal efficiency

$$
\eta_{t h}=\frac{w_{m}}{q_{a}}
$$

Unitary Thermal Consumption

$$
U T C=\frac{3600}{\eta_{t h} \eta_{p} \eta_{e}}
$$

with $\eta_{m}=\eta_{e}=1$

Specific Fuel Consumption

$$
S F C=\frac{3600 m_{f}}{P}
$$


Specific Steam Consumption

$$
S S C=\frac{3600 m_{S}}{P}
$$

where:

$w_{m}$ : Rate of Work by mass unit; [kJ/kg],

$q_{a}$ : Rate of Heat Transfer by mass; [kJ/kg],

$m_{f, s}$ : Fuel and Steam Flow; $\left[\mathrm{kg}_{\mathrm{c}} / \mathrm{s}, \mathrm{kg}_{\mathrm{v}} / \mathrm{s}\right]$,

$P$ : Pressure; [bar],

$h_{e}$ : Electrical Efficiency; [-],

$h_{p}$ : Mechanical Efficiency; [-].

To evaluate the above equations, thermodynamic properties per unit mass in each of the states in the steam cycle, temperature, pressure, enthalpy, entropy and volume, were found. Next, the balances of matter and energy were obtained in each of the equipment and processes involved in regenerative cycles and with these it is possible to obtain the fuel and steam flows.

\section{Results}

According with the operation conditions of Table 1, with variation of condensation pressure and the inlet steam of the turbine, and maintaining other operating conditions constant, the following results are obtained.

In Figure 3 it is shown the steam flow of water to generate a power of $160 \mathrm{MW}$. There is a decrease in the SSC when it operates with seven heaters for steam cycles with regeneration. When it operates with 2, 3, 4 and 5 heaters this decrease is approximately of $8.3 \%, 3.7 \%, 2.2 \%$ and $1.2 \%$ respectively. However, when compared to the regeneration with six and seven heaters, SSC has a decrease of $0.4 \%$, which means that the regeneration steam consumption decreases for power generation, because it increases the useful work and reduces the steam flow, as shown in Equation (5).

The same behavior with the SFC is shown in Figure 4, but when it operates with seven heathers the variation is slightly less than using $2,3,4,5,6$ heaters, which reduces by $6.2 \%, 2.5 \%, 1.5 \%, 0.9 \%$ and $0.3 \%$ respectively. This variation is more important than the previous due to the water is less expensive than the fuel burnt. Therefore, by increasing the number of heaters to eight would increase less than $0.3 \%$, in accordance with the tendency of Figures 3 and 5 :

The thermal efficiency at different pressures of condensation for steam cycles with regeneration is shown in Figure 5, it is observed that for all steam cycles a greater efficiency is achieved when the condensation pressure is 0.04 bar, likewise, it is shown that for the operating conditions the higher efficiency of the cycles is obtained when working with seven heaters (44.52\%), although the increase with respect to the cycle that has six heaters (44.39\%) is $0.13 \%$.

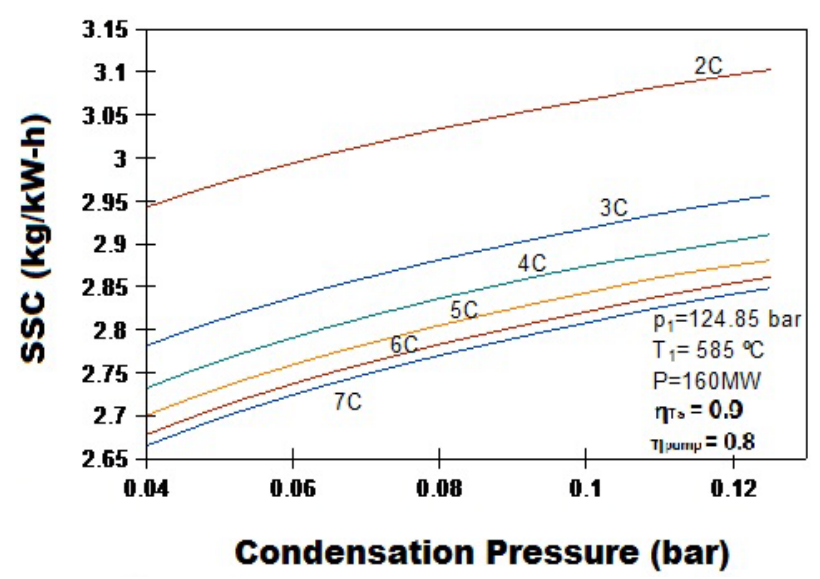

Figure 3. SSC to different pressure of condensation for steam cycles with regeneration. 


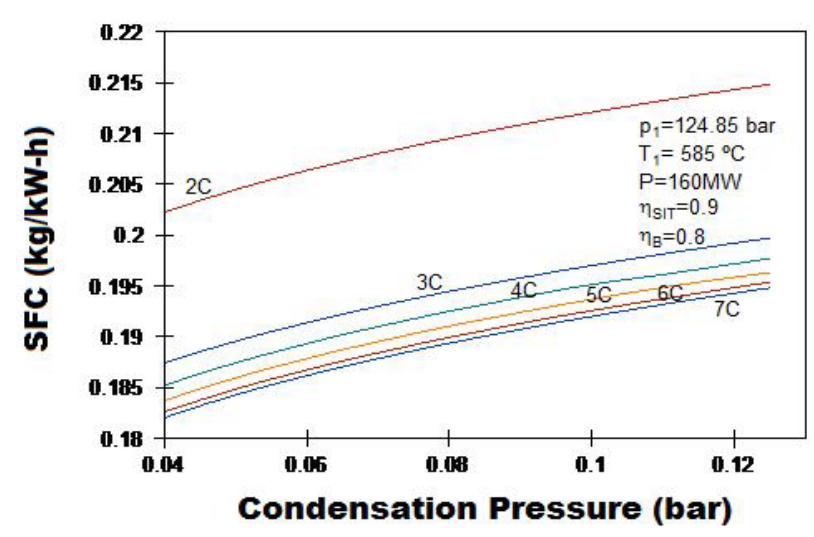

Figure 4. SFC to different pressure of condensation for steam cycles with regeneration.

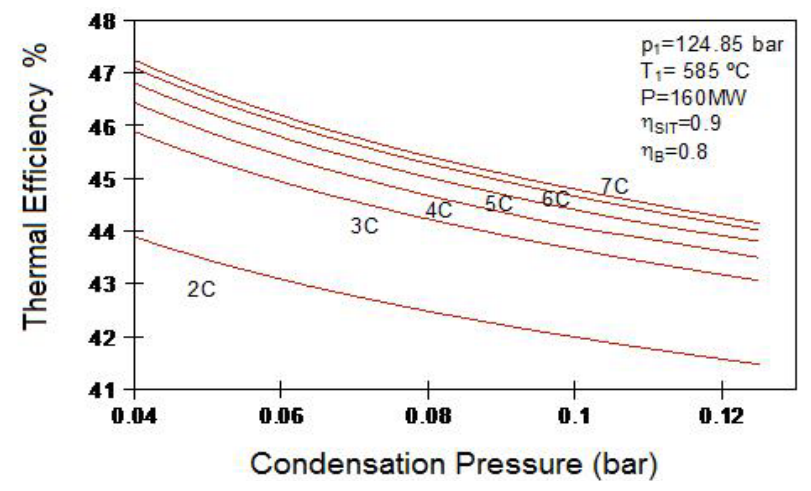

Figure 5. Thermal Efficiency to different pressures of condensation for steam cycles of regeneration.

The behavior of UTC at different pressures of condensation is shown in Figure 6, which shows that the difference between operating with seven or six heaters consists in providing approximately $24 \mathrm{~kJ} / \mathrm{kWh}$ therefore it is efficient to work with these cycles rather than 2, 3, 4, 5 which maintain a significant difference when compared with the seven heaters, 532, 208, 123, $70 \mathrm{~kJ} / \mathrm{kWh}$ respectively.

The difference in the operation of the steam cycles with regeneration with seven or six heaters, by varying the pressure of condensation and steam, is a little increment in the SFC. The SSC UTC and condensation at different pressures and different conditions at the turbine inlet are shown in Figure 7. The conditions of point " $a$ ": the UTC is $8085.61 \mathrm{~kJ} / \mathrm{kW}$-h and the SSC of $2825 \mathrm{~kg} / \mathrm{kW}$-h, maintaining the inlet pressure to the turbine and low condensing pressure in 0.077 bar results in a decrease of the UTC and the SSC by approximately $2.2 \%$ in point " $b$ ". The same decrease of these parameters is obtained by allowing the condensation pressure constant and increasing the steam pressure from 124.85 to 160 bar, but it requires a greater amount of steam flow, as the SSC increased, to generate $160 \mathrm{MW}$.

The behavior of the thermal efficiency and the useful work at different pressures is shown in Figure 8, where the behavior is similar to Figure 7. However, operating conditions where maximum thermal efficiency does not imply that it has a maximum useful work. Considering the same points of comparison of Figure 7 it must be achieved the same thermal efficiency in the point " $b$ " and " $c$ "; point " $b$ " is to be provided a larger amount of water.

The variation of the fuel flow when the operation is at different pressures of steam and condensation can be seen in Figure 9. By increasing the pressure at the inlet of the steam turbine, there is a decrease in fuel flow and the heat supplied, but this decrease is not higher than the one obtained when the condensing pressure decreases, e. g. for the conditions of the operating point to increase the pressure from 124.85 to 160 bar (points a and b) maintaining the pressure of $0.11 \mathrm{bar}$, there is a decrease of $0.18 \mathrm{~kg} / \mathrm{s}$. Now, if the pressure is maintaining at $124.85 \mathrm{bar}$ and the condensation pressure is decreased from 0.11 bar to 0.04 bar, the result is a decrease of $0.49 \mathrm{~kg} / \mathrm{s}$. 


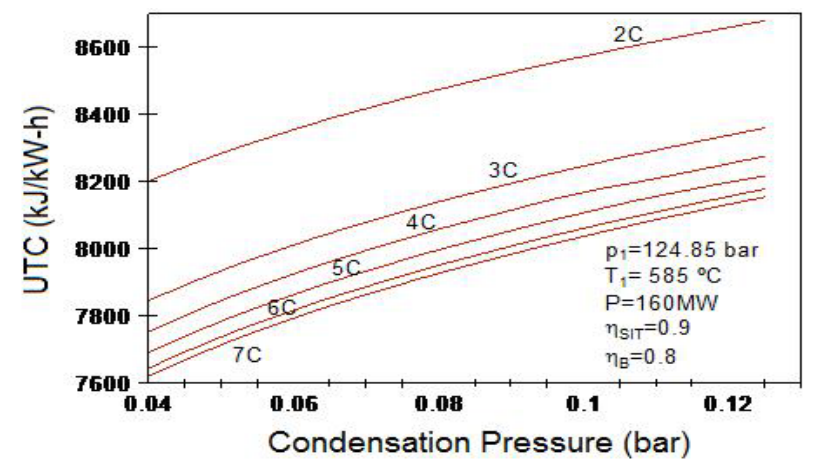

Figure 6. UTC to different pressure of condensation for steam cycles with regeneration.

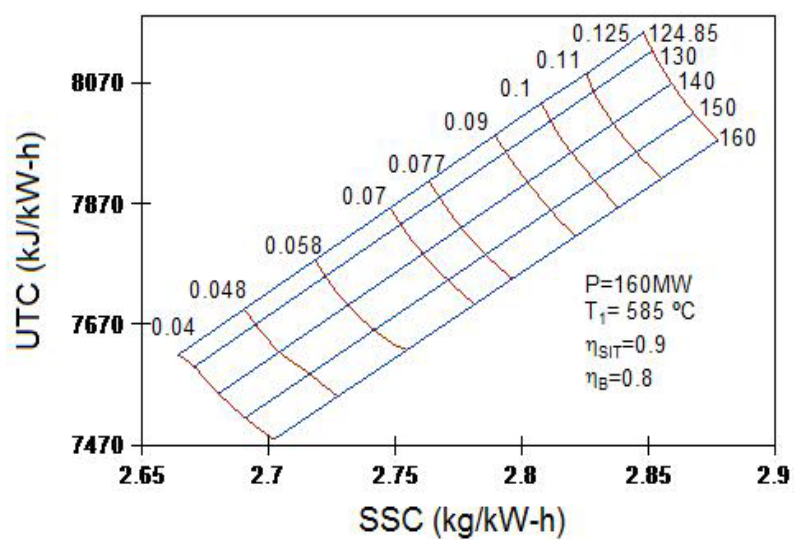

Figure 7. UTC and SSC to different condensation of pressure and different pressure in the inlet of the turbine of steam cycles with seven heaters.

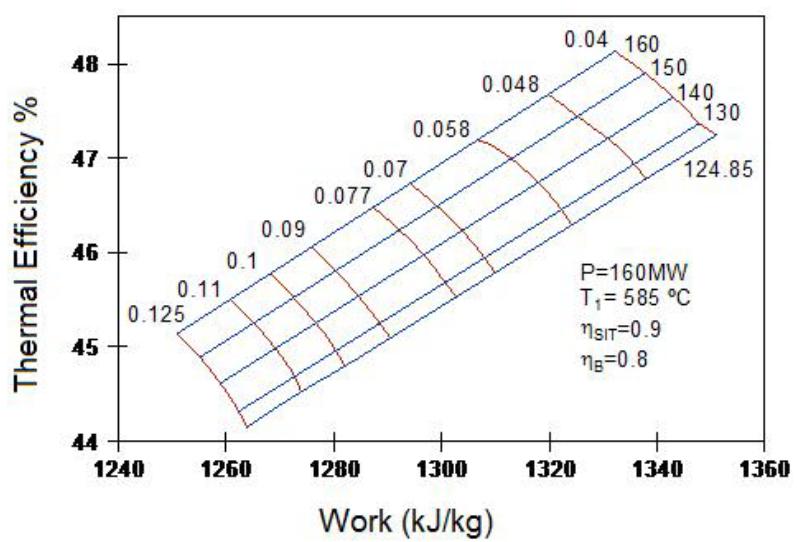

Figure 8. Thermal efficiency and useful work to different condensation pressures and turbine inlet steam cycle with seven heaters.

\section{Conclusion}

According to the energetic analysis performed in the regeneration cycles with six and seven heaters, the result is a difference in the values of SSC, SFC and UTC which is less than 0.5\%, likewise, it shows an increased thermal efficiency when heaters are added to the operating line, for preheating. As the heaters are added, the difference 


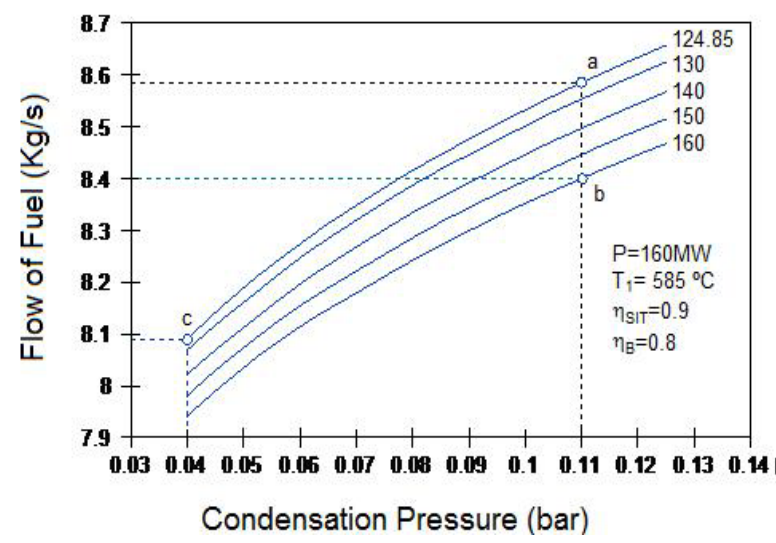

Figure 9. Fuel flow to different condensation pressures and turbine inlet steam cycle with seven heaters.

in increasing the thermal efficiency is reduced, leading to suggestions that eight heaters would not be desirable since it would have increased less than $0.5 \%$. Also, it is concluded that the increase or decrease of the condensing pressure and the inlet of the turbine plays a role on the energy cost for generating a kW-h.

\section{References}

[1] Malik, A.S., Boyko, O., Atkar, N. and Young, W.F. (2001) A comparative study of MR imaging profile of titanium pedicle screws. Acta Radiologica, 42, 291-293.

[2] Dincer, I. and Al-Muslim, H. (2001) Thermodynamic analysis of reheat cycle steam power plant. International Journal of Energy Research, 25, 727-739.

[3] Federal Electric Commission (2012) Catalogue of the thermoelectric plant in Ciudad Laredo. http://www.sener.gob.mx/res/PE_y_DT/pub/2012/PSE_2012_2026.pdf

[4] Bohem, R.F., et al. (1992) Thermodynamics and design, analysis and improvement of energy systems. ASME AES, 27, 154-155.

[5] Pereyra, M.S., Leyte, R.L., Aldaco, A.T. and González, R. (2005) Análisis energético y exergético del proceso de combustión en un generador de vapor. XI Congreso Internacional Anual de la SOMIM y IV Congreso Bolivariano de Ingeniería Mecánica, Morelia, 21-23 September 2005, 1-10.

[6] Pereyra, M.S., Leyte, R.L., Aldaco, A.T., Velázquez, M.T. and Mata, J.M.Z. (2003) Análisis exergético de una central termoeléctrica. VIII Congreso Latinoamericano de Turbomáquinaria, Boca del Rio, Veracruz, 14 October 2003, 1-9. 